\title{
Loss of immune homeostasis dictates SHIV rebound after stem-cell transplantation
}

Christopher W. Peterson, ${ }^{1,2}$ Clarisse Benne, ${ }^{3}$ Patricia Polacino, ${ }^{4}$ Jasbir Kaur, ${ }^{1}$ Cristina E. McAllister, ${ }^{1}$ Abdelali Filali-Mouhim, ${ }^{3}$ Willi Obenza, ${ }^{1}$ Tiffany A. Pecor, ${ }^{4}$ Meei-Li Huang, ${ }^{5}$ Audrey Baldessari, ${ }^{4}$ Robert D. Murnane, ${ }^{4}$ Ann E. Woolfrey, ${ }^{1,2}$ Keith R. Jerome, ${ }^{5,6}$ Shiu-Lok Hu, ${ }^{4,7}$ Nichole R. Klatt, ${ }^{4,7}$ Stephen DeRosa, ${ }^{5}$ Rafick P. Sékaly, ${ }^{3}$ and Hans-Peter Kiem ${ }^{1,2,8}$

'Division of Clinical Research, Fred Hutchinson Cancer Research Center, Seattle, Washington, USA.

2Department of Medicine, University of Washington, Seattle, Washington, USA. ${ }^{3}$ Department of Pathology, Case Western Reserve University, Cleveland, Ohio, USA. ${ }^{4}$ Washington National Primate Research Center, Seattle, Washington, USA. ${ }^{5}$ Division of Vaccine and Infectious Diseases, Fred Hutchinson Cancer Research Center, Seattle, Washington, USA. ${ }^{6}$ Department of Laboratory Medicine, ${ }^{7}$ Department of Pharmaceutics and ${ }^{8}$ Department of Pathology, University of Washington, Seattle, Washington, USA

The conditioning regimen used as part of the Berlin patient's hematopoietic cell transplant likely contributed to his eradication of HIV infection. We studied the impact of conditioning in simianhuman immunodeficiency virus-infected (SHIV-infected) macaques suppressed by combination antiretroviral therapy (cART). The conditioning regimen resulted in a dramatic, but incomplete depletion of $\mathrm{CD4}^{+}$and $\mathrm{CD} 8^{+} \mathrm{T}$ cells and $\mathrm{CD2O^{+ }} \mathrm{B}$ cells, increased $\mathrm{T}$ cell activation and exhaustion, and a significant loss of SHIV-specific Abs. The disrupted T cell homeostasis and markers of microbial translocation positively correlated with an increased viral rebound after CART interruption. Quantitative viral outgrowth and Tat/rev-induced limiting dilution assays showed that the size of the latent SHIV reservoir did not correlate with viral rebound. These findings identify perturbations of the immune system as a mechanism for the failure of autologous transplantation to eradicate HIV. Thus, transplantation strategies may be improved by incorporating immune modulators to prevent disrupted homeostasis, and gene therapy to protect transplanted cells.

Authorship note: C.W. Peterson and C. Benne contributed equally to this work.

Conflict of interest: The authors have declared that no conflict of interest exists.

Submitted: October 17, 2016 Accepted: December 19, 2016 Published: February 9, 2017

Reference information: JCI Insight. 2017;2(3):e91230. doi:10.1172/jici.nsight.91230.

\section{Introduction}

Strategies designed to eradicate or induce durable remission of latent HIV-1 infection face 2 major challenges: virus-infected immune cells, chiefly $\mathrm{CD}^{+} \mathrm{T}$ cells, must be destroyed, while broader innate and adaptive immune defenses must be retained $(1,2)$. The success of hematopoietic stem cell transplantation in eradicating HIV-1 in the Berlin patient highlights the importance of this intervention, as it remains the only HIV-1 functional cure described to date $(3,4)$. Hematopoietic stem cell transplantation involves several steps including the conditioning regimen and the stem cell graft. In the context of HIV cure approaches, the size of the latent viral reservoir is also important. The role of each one of these parameters must be dissected, as they all may have contributed to the Berlin patient's cure (5). The Berlin patient was removed from cART concurrent with his first transplant in February of 2007, when transplant-dependent immunodeficiency was most pronounced and the patient had not yet engrafted the donor cells which would facilitate the control of HIV (6). Thus, virus eradication/stable remission may have been achieved immediately following chemo- and radiotherapy conditioning regimens and allogeneic transplantation with CCR $5 \Delta 32$ donor cells.

The probability of finding an HLA-matched donor who is also homozygous for the CCR5 $\Delta 32$ null mutation is low, and the risks associated with allogeneic transplantation are high (7). Transplantation of HIV-protected cells in the autologous setting is safer than allogeneic transplantation and more readily available for patients (8-10). We have developed a model of cART-suppressed simian-human immunodeficiency viremia in the pigtail macaque (Macaca nemestrina). Our previous data demonstrate that the highly CCR5tropic HIV-env simian-human immunodeficiency virus (SHIV), SHIV-1157ipd3N4, establishes durable 
Table 1. Correlation between simian-human immunodeficiency virus peak viral rebound, T cell subsets, and microbial translocation markers

\begin{tabular}{|c|c|c|c|c|c|}
\hline Outcome & \multicolumn{2}{|c|}{ Marker $^{A}$} & $P$ value & rho value & FDR-corrected $P$ value \\
\hline \multirow{10}{*}{ Peak Viral Rebound } & $\mathrm{Ki}^{+} 7^{+} \mathrm{AUC}$ & Naive $\mathrm{CD}^{+}{ }^{+}$ & 0.0279 & 0.7857 & 0.1466 \\
\hline & & $\mathrm{CMCD}^{+}$ & 0.0576 & 0.7143 & 0.1822 \\
\hline & PD-1 AUC & $\mathrm{CM} \mathrm{CD8}^{+}$ & 0.0011 & 0.9524 & 0.024 \\
\hline & & $\mathrm{EM} \mathrm{CD8}^{+}$ & 0.0046 & 0.9048 & 0.0479 \\
\hline & & Naive $\mathrm{CD}^{+}$ & 0.0107 & 0.8571 & 0.075 \\
\hline & $\operatorname{SLAM}^{+} \mathrm{AUC}$ & Naive $\mathrm{CD}^{+}$ & 0.0167 & 0.9429 & 0.2 \\
\hline & & Post-Tx I & 0.0046 & 0.9048 & 0.219 \\
\hline & & Post-Tx II & 0.0279 & 0.7857 & 0.244 \\
\hline & sCD14 & Ac Post-Tx I & 0.0222 & 0.7807 & 0.244 \\
\hline & & ART WDI & 0.0114 & 0.8264 & 0.244 \\
\hline
\end{tabular}

${ }^{A} A U C$ was calculated for the indicated proliferative and immune checkpoint proteins as a function of transplant recovery, measured from pre-transplant (Pre-Tx) to necropsy time points. Time points are defined in Supplemental Table 1. Soluble CD14 (sCD14) and zonulin values were derived from the indicated single time point. CM, central memory T cells; EM, effector memory T cells; PD-1, programmed cell death protein 1.

infection in pigtail macaques, and can be suppressed by cART $(11,12)$. Pathogenicity in this species is consistent with available information for the closely related rhesus macaque (Macaca mulatta) $(13,14)$.

Total body irradiation/myeloablative conditioning results in many changes including lymphocyte depletion and damage to secondary lymphoid tissues such as the gastrointestinal (GI) tract (15-17). Here we defined the immunological mechanisms at play in SHIV-infected, cART-suppressed macaques following autologous transplantation in our well-established SHIV model.

\section{Results}

Study design. The experimental design of this study is shown in Figure 1A, and time points are listed in Supplemental Table 1; supplemental material available online with this article; https://doi.org/10.1172/ jci.insight.91230DS1. All animals underwent intravenous challenge with SHIV-1157ipd3N4 (SHIV-C), and cART was applied 6 months after infection as previously described (11). Peak viral loads (VLs) ranged between $10^{5}$ and $10^{7}$ copies $/ \mathrm{ml}$ plasma, and VL set points ranged between $10^{2}$ and $10^{5} \mathrm{copies} / \mathrm{ml}$ (Figure 1B) (18). After more than 24 weeks of cART, animals were well suppressed in peripheral blood ( $<30$ copies/ $\mathrm{ml}$ ) (Figure 1B), at which point they were separated into 2 cohorts of 5 animals; 1 animal from each group was excluded partway through the experiment owing to study-unrelated complications (see Methods). The control cohort was maintained on cART for a further 24 weeks with no other intervention. Animals in the transplanted cohort received autologous hematopoietic stem and progenitor cells following myeloablative conditioning. Hematopoietic recovery following myeloablative conditioning (1,020 cGy total body irradiation) and transplantation was consistent with previously published results in SHIV-naive animals (Supplemental Figure 1 and ref. 17). Following a total of more than 1 year on cART, all animals were released from cART and necropsied approximately 18 weeks later (Figure 1A). Consistent with past results, control and transplanted animals' plasma VLs rebounded with similar kinetics following cART withdrawal (19).

Increased rebound viremia in transplanted animals. VL rebound dynamics differed in the 2 cohorts of animals following CART withdrawal: transplanted animals displayed a significantly higher $(P=0.02)$ and sustained peak VL relative to controls (Figure 1C). We measured VLs in tissues collected from each animal at necropsy $(20,21)$ (Figure 1D). Average levels of viral DNA in tissues were increased up to 92-fold in transplanted animals relative to controls, while viral RNA levels were increased greater than 3 logs in many tissues, including lymph nodes and GI tract. Tissue viremia was significantly correlated with peak VL rebound in plasma (Supplemental Table 2). These data indicate that VL rebound was significantly increased in transplanted animals, relative to controls, following cART withdrawal.

Myeloablative TBI-based conditioning leads to robust depletion of peripheral $T$ cells. We measured changes in $\mathrm{T}$ cell counts, phenotype, and distribution following total body irradiation (TBI). We observed an average 
24 weeks

54 weeks

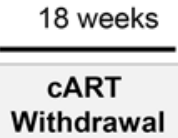

\begin{tabular}{|c|c|c|c|c|}
\hline 6 weeks & 24 weeks & 27 weeks & 27 weeks & 18 weeks \\
\hline Baseline & SHIV-C Challenge & 3-Drug cART & Transplant & $\begin{array}{c}\text { CART } \\
\text { Withdrawal }\end{array}$ \\
\hline
\end{tabular}
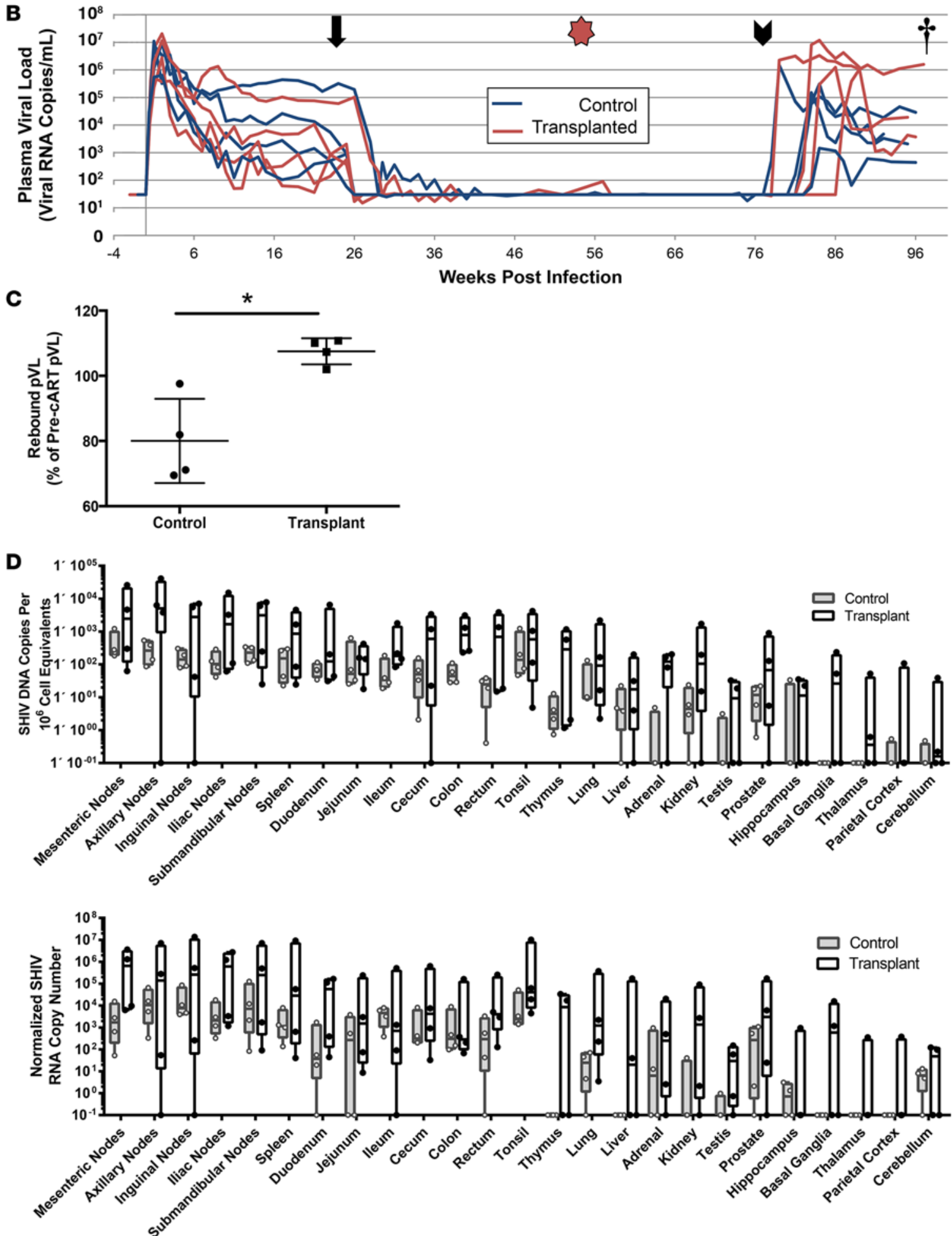
Figure 1. SHIV rebound is increased in transplanted animals following cART withdrawal. (A) Two groups of 5 animals were analyzed in this study. Prior to infection, baseline measurements were collected over 6 weeks. Following intravenous virus challenge with simian-human immunodeficiency virus 1157ipd3N4 (SHIV-C), infection progressed for 6 months prior to initiation of combination antiretroviral therapy (cART). Untransplanted animals (upper panel) remained on CART for approximately 1 year, followed by cART withdrawal and necropsy 15-20 weeks later. Transplanted animals (lower panel) were treated identically, except for hematopoietic stem cell transplantation conducted 6 months following initiation of cART, using autologous $\mathrm{CD} 34^{+}$cells cryopreserved prior to infection. One untransplanted and 1 transplanted animal were excluded partway through the study due to unrelated health issues; data were included where applicable. (B) At the indicated times following SHIV infection, plasma viral load (pVL) was measured by quantitative PCR (QPCR) from transplanted animals (red lines) or untransplanted animals (blue lines). Arrow, cART initiation; star, autologous transplant; arrowhead, cART withdrawal; dagger, necropsy. (C) Ratio of viremia following post-cART viral rebound to comparable time points during primary infection (see Methods). Data are the mean \pm SD. (D) The indicated tissues were collected at necropsy from untransplanted (gray bars) and transplanted animals (white bars). Total genomic DNA and RNA were extracted for viral nucleic acid measurements by QPCR. Total SHIV DNA (upper panel) was normalized to a genomic DNA standard (macaque RNaseP p30, MRPP30). SHIV genomic RNA (lower panel) was normalized to the crossing threshold value of MRPP30. Boxes represent median and 25th/75th percentiles, and whiskers represent minimum/maximum values for 4 animals in each cohort. ${ }^{*} P<0.05$ by 2-tailed Mann-Whitney test.

10-fold decrease in the absolute number of total $\mathrm{CD}^{+}$and $\mathrm{CD} 8^{+} \mathrm{T}$ cells at post-transplant nadir (Figure 2 , A and B). We asked whether the lack of immune reconstitution in the transplanted cohort could be explained by a decrease in the numbers of naive $\mathrm{T}$ cells $\left(\mathrm{T}_{\mathrm{N}}\right)(22)$ and their proximal progeny, central memory $\mathrm{T}$ cells $\left(\mathrm{T}_{\mathrm{CM}}\right)$. Absolute numbers of all $\mathrm{CD}^{+}$and $\mathrm{CD}^{+}$naive and memory $\mathrm{T}$ cell subsets (Figure 2 , D-I) and many $\mathrm{Ki}^{+} 7^{+}$, programmed cell death protein 1 -positive $\left(\mathrm{PD}-1^{+}\right.$), and HLA-DR ${ }^{+}$subsets (Supplemental Figure 2) were significantly decreased at early time points that followed TBI. Both $\mathrm{CD} 4^{+}$and $\mathrm{CD} 8^{+}$ $\mathrm{T}_{\mathrm{N}}$ remained at significantly lower levels in the transplanted group as compared with control animals at all time points prior to cART withdrawal (Figure 2, D and G). $\mathrm{CD}^{+} \mathrm{T}_{\mathrm{CM}}$ and $\mathrm{CD}^{+}$effector memory $\mathrm{T}$ cell $\left(\mathrm{T}_{\mathrm{EM}}\right)$ numbers were also significantly lower in transplanted animals at all time points measured prior to cART withdrawal (Figure 2, H and I). Redistribution of these cells to tissues did not contribute to the persistently decreased $\mathrm{CD}^{+} \mathrm{T}$ cell levels observed in blood, as numbers of $\mathrm{T}_{\mathrm{N}}$ and $\mathrm{T}_{\mathrm{CM}}$ in the gut did not increase following transplantation (data not shown). In contrast, $C D 4^{+} \mathrm{T}_{\mathrm{CM}}$ and $\mathrm{T}_{\mathrm{EM}}$, but not $\mathrm{T}_{\mathrm{N}}$ recovered to levels that were comparable to those of controls by the time cART was withdrawn (Figure 2, E and F). These findings indicate that myeloablative conditioning leads to a significant depletion of peripheral $\mathrm{T}$ cells, especially in $\mathrm{T}_{\mathrm{N}}$ and $\mathrm{T}_{\mathrm{CM}}$ lineages.

TBI leads to a transient loss of B cells and a durable loss of SHIV-specific B cells. Peripheral CD20+ B cell counts were also decreased an average of 300 -fold in transplanted animals. B cell numbers were restored within 4 to 6 weeks after engraftment (Figure 2C). Despite the recovery of B cell numbers, we observed a significant loss of HIV-1- and SIVmac239-specific Ab titers (Figure 3, A and B). Area under the curve (AUC) measurements were lower in the transplanted cohort prior to cART withdrawal (HIV-1 gp120 titer, $P=0.028$ ) and through cART withdrawal (SIVmac239 titer, $P=0.0286$; HIV-1 gp120 titer, $P=$ 0.057), showing that SHIV-specific B cells were depleted and/or that lack of CD4 ${ }^{+} \mathrm{T}$ cells may impact B cell function in transplanted animals (Figure 3, C and D). Following cART interruption, SHIV-specific $\mathrm{B}$ cell responses in control animals increased compared with the transplanted group (SIVmac239 titer, $P=0.028$; HIV-1 gp120 titer, $P=0.057$ ) (Figure 3C). Restoration of SHIV-specific Ab titers after cART withdrawal was negatively correlated with the absolute $\mathrm{CD}^{+} \mathrm{T}$ cell changes (Supplemental Table 3 ). Moreover, transplanted animals failed to increase SHIV-specific Ab titers upon cART treatment (Figure 3). These results highlight the importance of $\mathrm{CD} 4^{+} \mathrm{T}$ cell help for the development and maintenance of SHIV-specific Ab responses

Robust immune activation following transplantation correlates with magnitude of VL rebound. The enhanced VL rebound in transplanted animals could be attributed to $\mathrm{T}$ cell activation/homeostatic expansion coincident with lymphopenia (23-25). Following autologous transplantation, the proportion of T cells expressing Ki67 was significantly increased in the majority of $\mathrm{CD}^{+}$and $\mathrm{CD} 8^{+} \mathrm{T}$ cell subsets in the transplanted group (Figure 4). Significant differences in the proportion of PD- $1^{+} \mathrm{T}_{\mathrm{CM}}$ (Figure 5), HLA-DR ${ }^{+} \mathrm{CD} 4^{+} \mathrm{T}_{\mathrm{N}}, \mathrm{HLA}$ $\mathrm{DR}^{+} \mathrm{CD}^{+} \mathrm{T}_{\mathrm{CM}}$, and HLA-DR ${ }^{+} \mathrm{CD}^{+} \mathrm{T}_{\mathrm{CM}}$ subsets were also observed (Figure 6). Expression of PD-1 on $\mathrm{CD}^{+} \mathrm{T}$ cell subsets and SLAM/CD150 on $\mathrm{CD}^{+}$and $\mathrm{CD} 8^{+} \mathrm{T}_{\mathrm{N}}$ subsets were positively correlated to peak VL rebound following cART withdrawal at all time points after transplantation (Table 1 and Supplemental Table 4). Next, we used Boolean analysis to quantify the coexpression of at least 2 immune checkpoint proteins (ICPs: PD-1, CTLA4, SLAM/CD150, and TIGIT) on $\mathrm{CD}^{+}$and $\mathrm{CD} 8^{+} \mathrm{T}$ cell subsets in control and transplanted nonhuman primates (NHPs), as these profiles indicate HIV reservoir size (26) and T cell exhaustion (27). We found a statistically significant positive correlation between expression of various ICP 
A
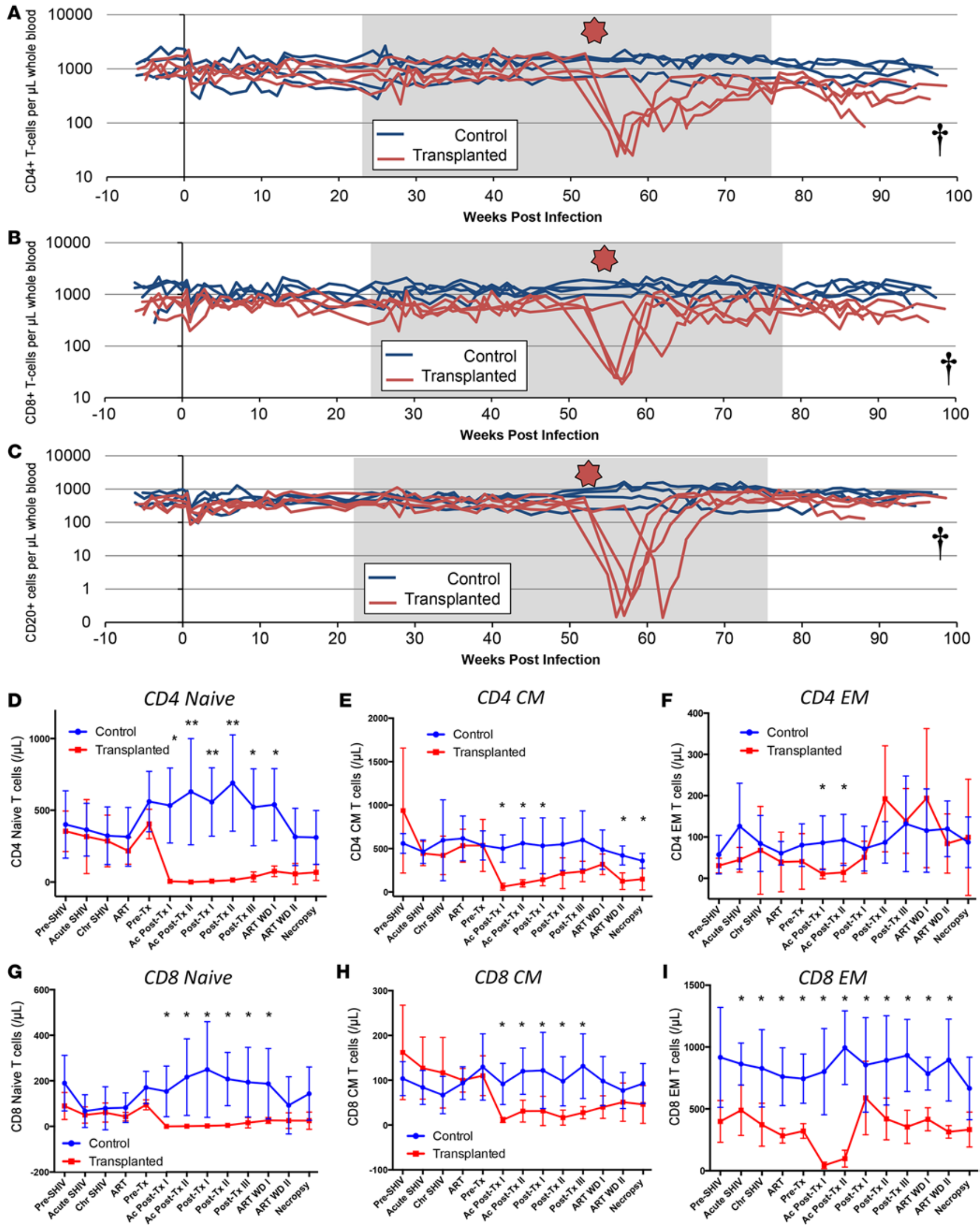

Figure 2. Peripheral T cell subsets and $\mathrm{CD}^{2} \mathrm{O}^{+} \mathrm{B}$ cells are significantly depleted following autologous transplantation. Absolute numbers of peripheral blood $\mathrm{CD3}^{+} \mathrm{CD}^{+} \mathrm{T}$ cells $(\mathbf{A}), \mathrm{CD3}^{+} \mathrm{CD}^{+} \mathrm{T}$ cells (B), and $\mathrm{CD2O} \mathrm{O}^{+} \mathrm{B}$ cells (C) were quantified by complete blood cell (CBC) counts and flow cytometry from transplanted animals (red lines) and untransplanted animals (blue lines), and plotted as a function of weeks after infection with simian-human immunodeficiency virus 
1157ipd3N4 (SHIV-C). Batched flow analyses and CBC data were used to calculate absolute numbers of CD4 ${ }^{+}$naive (D), CD4 ${ }^{+}$central memory (CM, E), CD4 effector memory (EM, F), CD8 ${ }^{+}$naive (G), CD8+ CM (H), and CD8+ EM subsets (I). Star, autologous transplant; dagger, necropsy. Values in D through I represent mean \pm SD. ${ }^{*} P<0.05,{ }^{*} P<0.01$ by 2 -tailed Mann-Whitney test. Time points along the $x$ axes in $\mathbf{D}$ through I are defined in Supplemental Table 1 .

combinations in T cell subsets and the peak VL rebound observed in animals following cART withdrawal (Supplemental Tables 5 and 6). For example, the simultaneous expression of PD-1, SLAM/CD150, and TIGIT was increased in peripheral $\mathrm{CD}^{+} \mathrm{T}_{\mathrm{N}}$ cells from transplanted animals, and was positively correlated to VL rebound. These results suggest that the homeostatic expansion and the immune exhaustion that follows myeloablation and transplantation provide a favorable milieu for SHIV replication and dissemination in peripheral blood and in tissues following cART withdrawal, consistent with increased VL rebound (Figure 1C) and increased levels of virus in tissues in transplanted animals (Figure 1D).

Microbial translocation markers correlate with VL rebound. We screened serum samples for a panel of markers of microbial translocation, as myeloablative conditioning can trigger gut damage and microbial translocation (28-30) (Figure 7, A-C). Zonulin, a marker of gut epithelium tight junctions and gut integrity, was significantly increased during transplant recovery, and remained higher following cART withdrawal $(P=$ 0.0159 at post-transplant time point I [post-Tx I], $P=0.031$ at post-Tx II, $P=0.028$ at cART withdrawal (ART WD in figure), and $P=0.057$ at necropsy) (Figure 7A). Importantly, zonulin significantly correlated with peak VL rebound (Table 1). Serum levels of soluble CD14 (sCD14), a marker of microbial translocation and monocyte activation $(31,32)$, were comparable between transplanted and control animals during suppressive cART, but were elevated at the terminal necropsy time point following cART withdrawal $(P$ $=0.028$ ) (Figure 7C), suggesting further aggravation of gut damage following VL rebound. Plasma levels of sCD14 were also positively correlated to peak VL upon cessation of cART (Table 1). The impact of microbial translocation on immune homeostasis has been associated with the upregulation of several proinflammatory and antiinflammatory cytokines $(33,34)$. Indeed, zonulin and sCD14 were positively associated with serum levels of lipopolysaccharide binding protein (LBP), monocyte chemoattractant protein-1 (MCP-1), and IL-10, and negatively associated with levels of TGF- $\alpha$ (Supplemental Table 7). LBP, MCP-1, TGF- $\alpha$, and IL- 8 were present at higher levels in transplanted animals (Figure 7, D-G). MCP-1 and LBP negatively correlated with $\mathrm{CD}^{+} \mathrm{T}_{\mathrm{N}}$ and total $\mathrm{CD}^{+} \mathrm{T}$ cell AUC (Supplemental Table 8). Zonulin and sCD14 were positively associated with $C D 8^{+} \mathrm{PD}-1^{+} \mathrm{T}_{\mathrm{CM}}$ AUC (Supplemental Table 9). These associations likely underlie a complex crosstalk between gut damage, microbial translocation, cytokine expression, and $\mathrm{T}$ cell reconstitution in transplanted, $\mathrm{SHIV}^{+}$animals that all impact VL rebound.

The size of the latent SHIV reservoir does not correlate with VL rebound. Conditioning led to a substantial loss of $\mathrm{CD}^{+} \mathrm{T}$ cells in our transplanted animals, but residual $\mathrm{CD} 4^{+} \mathrm{T}$ cells were highly activated and proliferative following transplantation. To quantify the impact of transplantation on the size of the latent SHIV reservoir, we developed a SHIV-adapted quantitative viral outgrowth assay (QVOA), and Tat/rev-induced limiting dilution assay (TILDA) to measure reservoir size before and after transplantation ( 6 and 11 months after initiation cART). In 4 control animals, changes in the size of the reservoir between the 2 time points were variable by QVOA. Two animals exhibited a 4- to 7-fold decrease in reservoir size, while 2 showed a mild increase of 2-fold or less (Figure 8A). In the 4 transplanted animals, QVOA showed that reservoir size was maintained, or decreased to undetectable levels, and hence did not correlate with the increased VL rebound that was observed following cART withdrawal. Results from TILDA showed that the average size of the viral reservoir decreased proportionally in control animals and transplanted animals (Figure 8B). No correlation was observed in these reservoir measurements, likely owing to the fact that TILDA measures expression of multispliced viral RNA, while QVOA measures production of replication-competent virions (Supplemental Figure 3). These findings suggest that transplantation did not increase the size of the peripheral viral reservoir; as such, a larger reservoir is unlikely to underlie the increased VL rebound we observed in transplanted animals.

\section{Discussion}

Here we show that disrupted immune homeostasis after autologous transplantation with TBI conditioning, rather than an increase in the size of the viral reservoir, is responsible for increased VL rebound following cART withdrawal. These data reinforce the importance of immune activation and dysfunction in driving viremia. Specifically, we show that expression of markers of proliferation, microbial translocation, and inflammation are predictive of increased peak plasma VL rebound following cART withdrawal in 
A

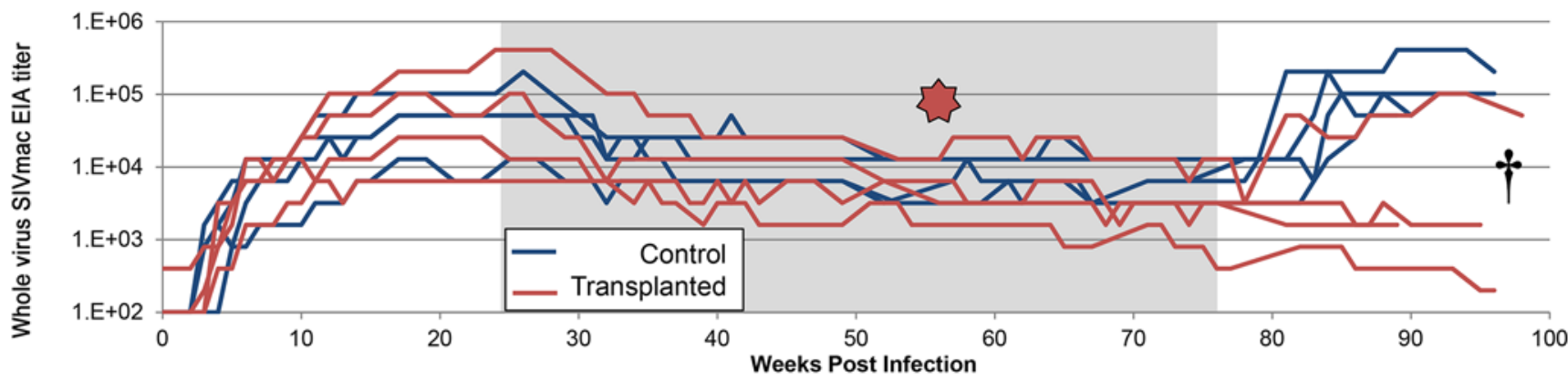

B

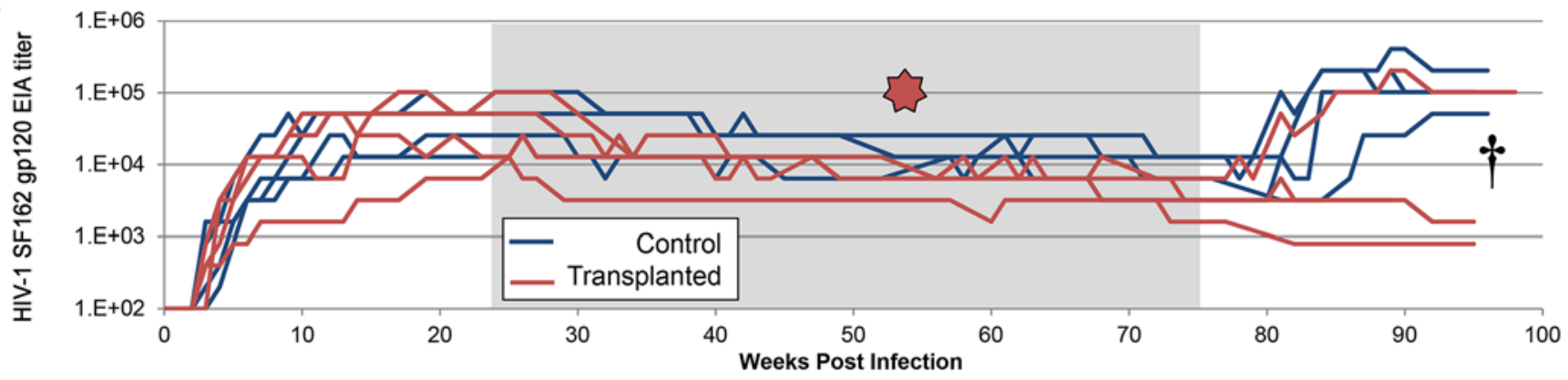

C

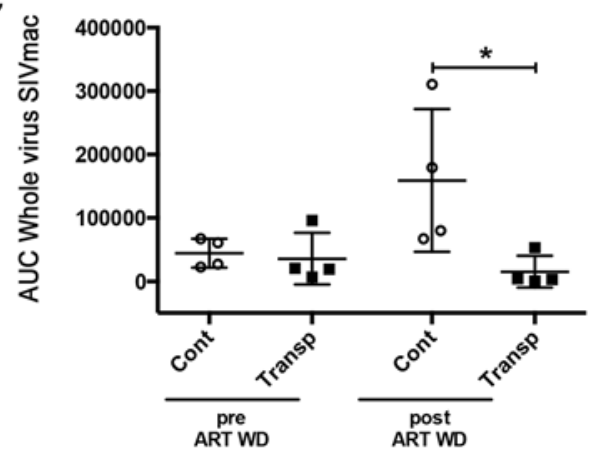

D

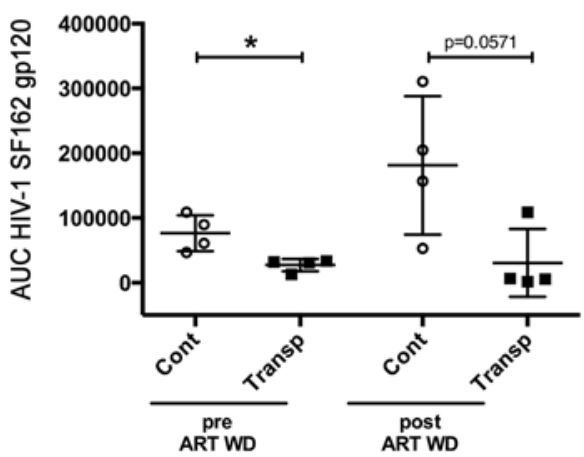

Figure 3. SHIV-specific B-cell function is significantly impaired following autologous transplantation. Serum titers of antibodies specific for the SIV (A) or HIV (B) portions of simian-human immunodeficiency virus 1157ipd3N4 (SHIV-C) were measured by ELISA. Star, autologous transplant; dagger, necropsy. AUC was calculated from pre-transplant to combination antiretroviral therapy (cART) withdrawal (pre-ART WD) and from cART withdrawal to necropsy (post-ART WD) for anti-SIV (C) and anti-HIV (D) antibody titers. Values in C and $\mathbf{D}$ represent mean \pm SD. ${ }^{*} P<0.05$ by 2 -tailed Mann-Whitney test. Near-significant $P$ values are also indicated.

transplanted animals, and are associated with higher levels of SHIV DNA and RNA in tissues following rebound (see proposed model in Supplemental Figure 4). Our studies highlight the importance of an intact immune system for viral control after cART withdrawal.

GI damage has emerged as a hallmark of chronic immune signaling during suppressed infection in $\mathrm{HIV}^{+}$patients and in SIV and SHIV models, contributing both to reservoir maintenance and disease progression (35-38). Our findings suggest that transplantation, particularly TBI, may exacerbate this vicious cycle by disrupting the integrity of the mucosal barrier. We observed an increase in multiple serum markers of microbial translocation in our transplanted animals, relative to untransplanted controls, and importantly, zonulin and sCD14 correlated with post-cART VL rebound (Figure 7, A-C, and Table 1). Our model predicts that these markers trigger increased expression of several proinflammatory cytokines (Supplemental Table 7) $(29,30)$. These data emphasize that restoration of immune homeostasis to pretransplant levels in the GI tract and other mucosal tissues is critical for any analytical treatment interruption (ATI) protocol. Furthermore, decreased gut integrity may underlie altered immunity and inflammatory responses after transplantation.

At 18 to 25 weeks after transplantation (immediately prior to cART withdrawal), peripheral $\mathrm{T}$ cells, particularly naive cells, had not fully recovered, despite displaying a higher percentage of activation and 
A

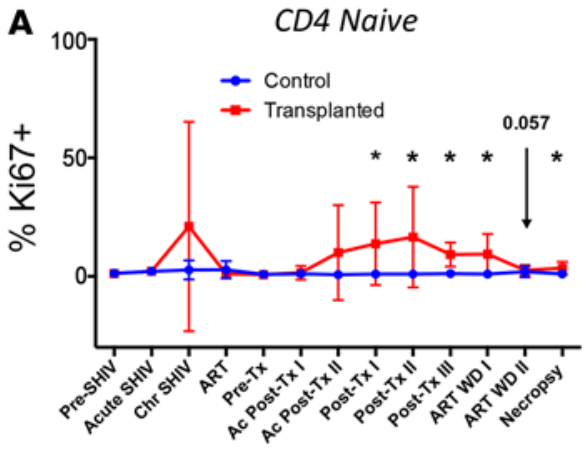

D

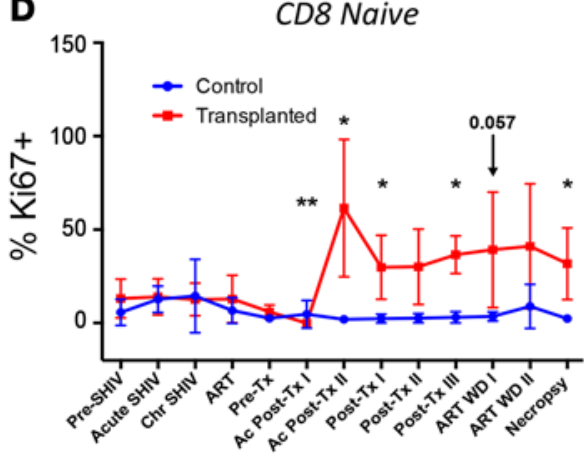

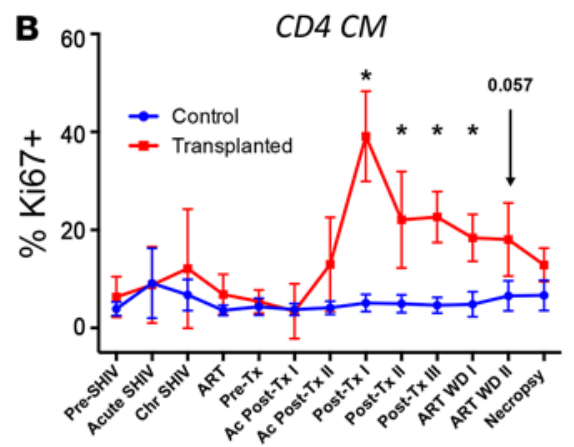

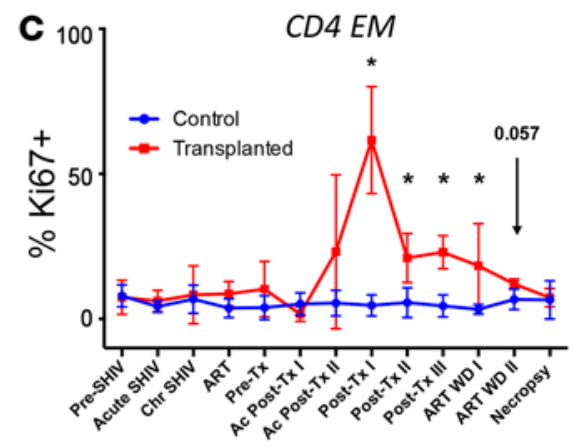

E

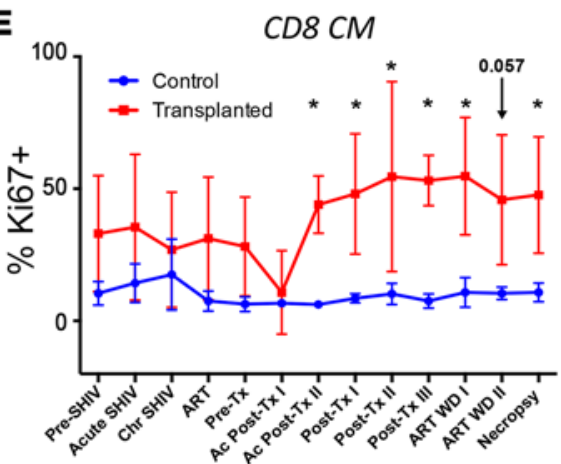

$\mathbf{F}$

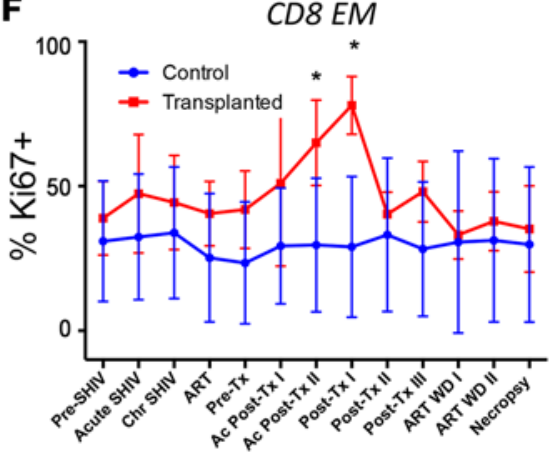

Figure 4. Significant increase in $\mathrm{CD}^{+}{ }^{+} \mathrm{Ki} 67^{+}$and $\mathrm{CD8}{ }^{+} \mathrm{K} \mathbf{K} 67^{+}$subset proportions following autologous transplantation. At the indicated time points, flow cytometry was used to analyze batched peripheral blood mononuclear cell (PBMC) samples for expression of the proliferation marker Ki67 in CD4 ${ }^{+}$(A-C) and $C D 8^{+} T$ cells $(\mathbf{D}-\mathbf{F})$. Naive, central memory $(C M)$, and effector memory (EM) subsets are shown. Values represent mean $\pm S D$. ${ }^{*} P<0.05$, ${ }^{* *} P<0.01$ by 2-tailed Mann-Whitney test. Near-significant $P$ values are also indicated. Time points along the $x$ axes are defined in Supplemental Table 1.

proliferation markers. High levels of $\mathrm{T}$ cell proliferation are a hallmark of lymphopenic environments (39, 40). This failure to reconstitute CD4 numbers could be the result of deficits in absolute T cell production, as low levels of $\mathrm{CD} 4^{+}$and $\mathrm{CD} 8^{+} \mathrm{T}_{\mathrm{N}}$ were observed in transplanted animals. Moreover, Ki67 ${ }^{+} \mathrm{CD} 4^{+} \mathrm{T}$ cells have been associated with increased susceptibility to infection $(23,41)$ and HLA-DR and PD-1 expression in $\mathrm{CD} 4^{+} \mathrm{T}$ cells is strongly associated with $\mathrm{CD} 4^{+} \mathrm{T}$ cells that are positive for integrated HIV DNA (42). Other ICPs, including TIGIT, have been shown to mark the latent HIV reservoir $(26,43)$. We show here that expression of these markers is upregulated in transplanted animals relative to controls. Following myeloablative conditioning, $\mathrm{Ki} 67^{+}$as well as $\mathrm{PD}-1^{+}$cells may represent a homeostatic response (refilling the niche) or an antigen-specific response (repopulating adaptive immune cells as cognate antigens reemerge) $(44,45)$. The increased frequency of cells that express these markers in stably suppressed animals following autologous transplantation strengthens the paradoxical notion that despite a reduction of susceptible $\mathrm{T}$ cells, immune reconstitution following myeloablation provided the virus with an opportunity to persist and disseminate. This hypothesis is also supported by studies depleting $\mathrm{CD} 4^{+} \mathrm{T}$ cells in the context of SIV, whereby viremia was highly associated with the level of $\mathrm{Ki} 67^{+} \mathrm{CD} 4^{+} \mathrm{T}$ cells (46). Following myeloablation, we observed persistent increases in the frequency of exhausted $\mathrm{CD}^{+} \mathrm{T}$ cells, loss of SHIV-specific Ab responses, and greater proportions of infection-susceptible target cells (i.e., activated $\mathrm{CD} 4^{+} \mathrm{T}$ cells). This led to a functionally impaired cellular and humoral immune system, creating an ideal environment for robust viral replication once cART was discontinued (Supplemental Figure 4).

We observed sustained reactivation of viral reservoirs in animals following cART withdrawal, independent of transplantation. When each animal's rebound viremia was compared with its own data from primary infection, plasma VL rebound in transplanted animals was significantly higher than controls; this trend was also observed in tissues. A primary question is the extent to which the conditioning regimen, in our case TBI, depletes $\mathrm{CD} 4^{+} \mathrm{T}$ cells in various reservoir tissues, relative to the degree of depletion we observe in peripheral blood. Interestingly, a recent imaging study in NHPs indicates that TBI is inefficient in depleting $\mathrm{CD} 4^{+}$cells in tissues, as $\mathrm{CD} 4$ counts are highly variable upon TBI, ranging from $36 \%$ to $40 \%$ depletion in the spleen to $73 \%$ to $92 \%$ depletion in axillary lymph nodes (16). 
A
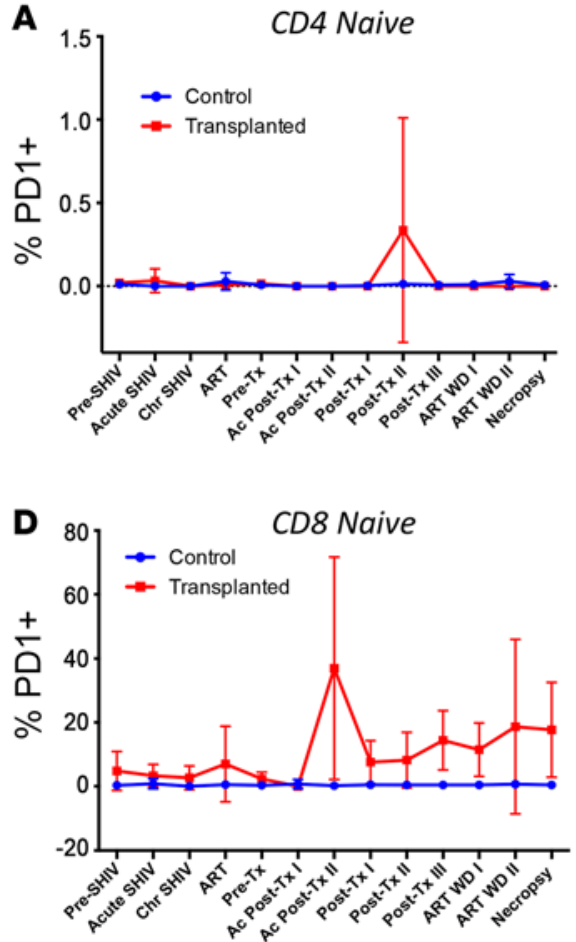

B
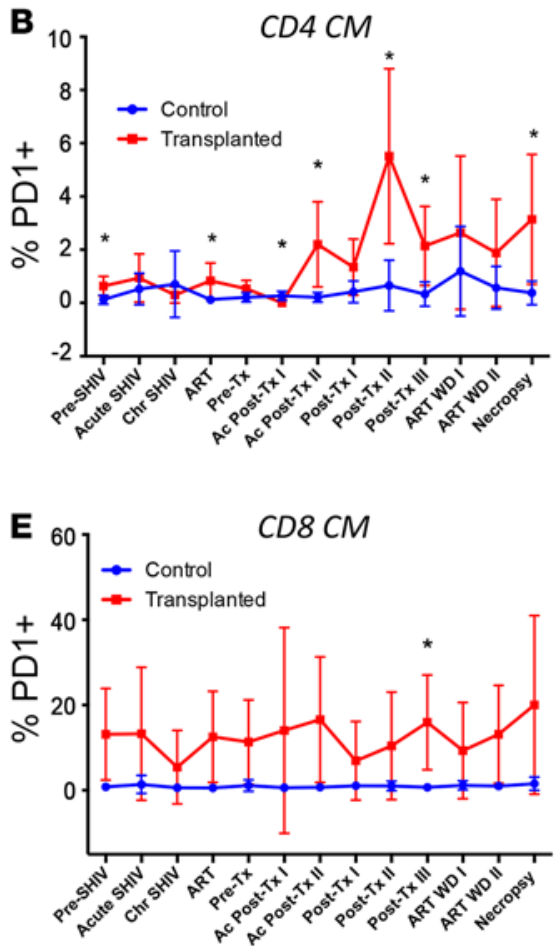

C
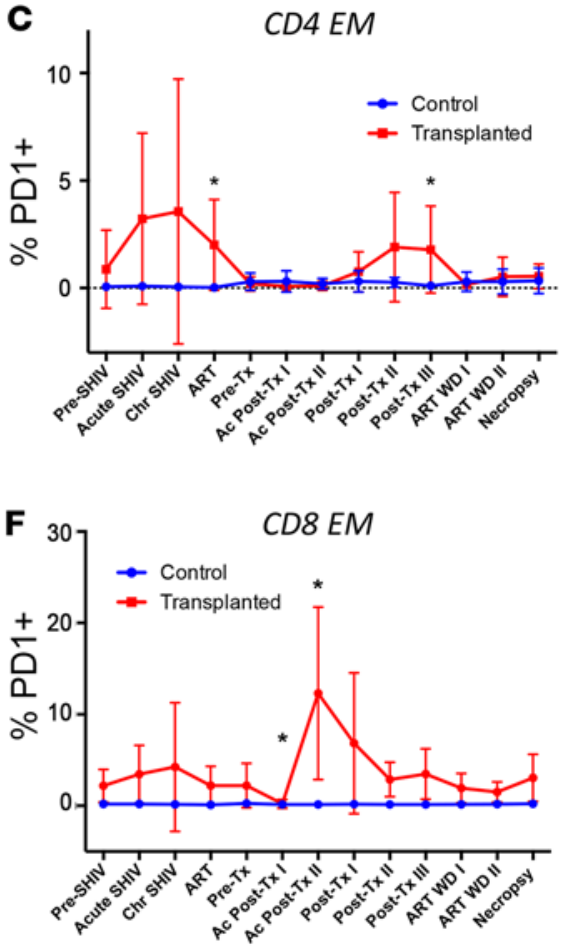

Figure 5. Significant increase in CD4 ${ }^{+}$PD $-1^{+}$and CD8 + PD-1+ subset proportions following autologous transplantation. At the indicated time points, flow cytometry was used to analyze batched peripheral blood mononuclear cell (PBMC) samples for expression of the proliferation/exhaustion marker PD-1 in $\mathrm{CD}^{+}(\mathbf{A}-\mathbf{C})$ and $C D 8^{+} \mathrm{T}$ cells $(\mathbf{D}-\mathbf{F})$. Naive, central memory $(\mathrm{CM})$, and effector memory (EM) subsets are shown. Values represent mean $\pm \mathrm{SD}$. ${ }^{*} P<0.05$ by 2-tailed Mann-Whitney test. Time points along the $x$ axes are defined in Supplemental Table 1.

As such, tissues that retain a greater percentage of $\mathrm{CD} 4^{+}$cells following myeloablative conditioning are also likely to be the most potent sanctuaries for latently infected cells, which could explain the higher rebound observed in transplanted NHPs $(47,48)$.

Our findings are consistent with past studies showing that autologous transplantation in stably suppressed $\mathrm{HIV}^{+}$patients is safe, but insufficient for HIV eradication $(9,49)$. Recent allogeneic transplant patients (the Boston patients) that were $\mathrm{HIV}^{+}$and stably suppressed were maintained on cART for at least 1,000 days after transplantation, prior to ATI. Although no replication-competent virus could be detected prior to ATI, both rebounded following ATI. This is in stark contrast to the Berlin patient: cART was withdrawn concurrent with transplantation, and no replication-competent virus has been detected after nearly 10 years. The Boston patients' donor cells were not protected from HIV as in the Berlin patient, allowing virus to spread rapidly; we made similar observations in our study. Furthermore, the Boston patients remained on immunosuppressive therapy at the time of ATI, which likely also suppressed HIV-specific immune responses. These findings strongly emphasize the importance of a fully recovered immune system and HIV-protected cells prior to any ATI in HIV cure trials.

Our data highlight the importance of several immune parameters, including markers of $\mathrm{T}$ cell proliferation/activation, B cell function, and microbial translocation as better predictors quantifying the safety of ATI study on a per-patient basis. The restoration of pretransplant levels of immune activation, function, and gut homeostasis should be a prerequisite for consideration of ATI. A number of immunotherapies currently being applied to cancer patients may prove useful in $\mathrm{HIV}^{+}$transplant patients. PD-1 blockade $(50,51)$ may reverse the immune exhaustion phenotype we observed in our study. Ab-based therapies, namely HIV broadly neutralizing Abs $(52,53)$ could be applied during acute cART withdrawal, providing a substitute for the absence of SHIV-specific Abs caused by myeloablation. Finally, rapamycin is a well-established therapy following allogeneic stem cell and renal transplants (54). As it has been shown to impact immune senescence and restore immune function (55), it may also address the immune exhaustion phenotype we observe following autologous transplantation. Regardless of whether viral reservoir measurements suggest eradication in a cART-suppressed patient, an immune system with well-regulated 
A
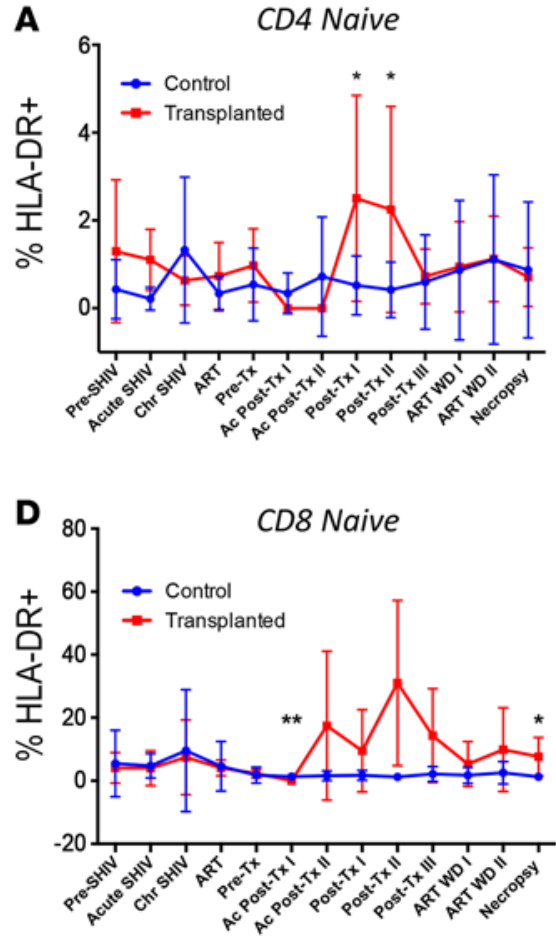

B
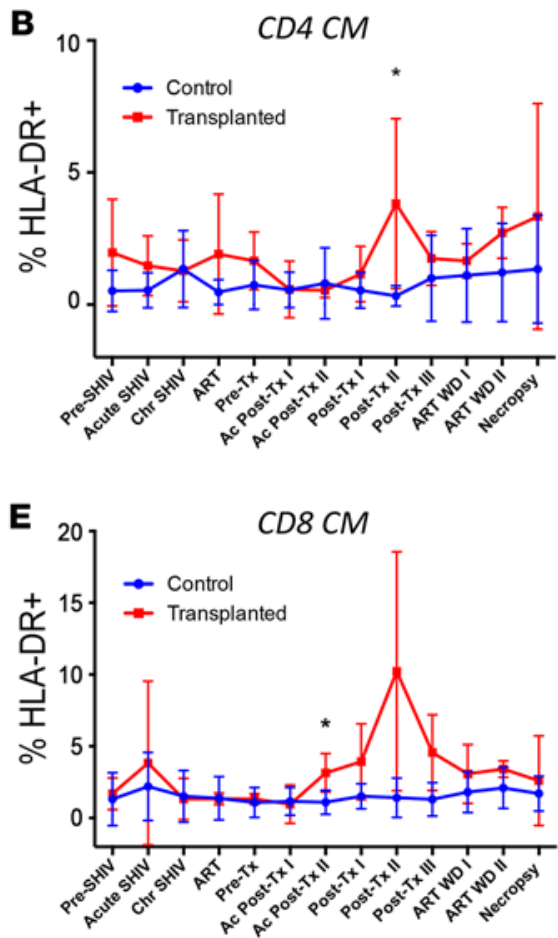

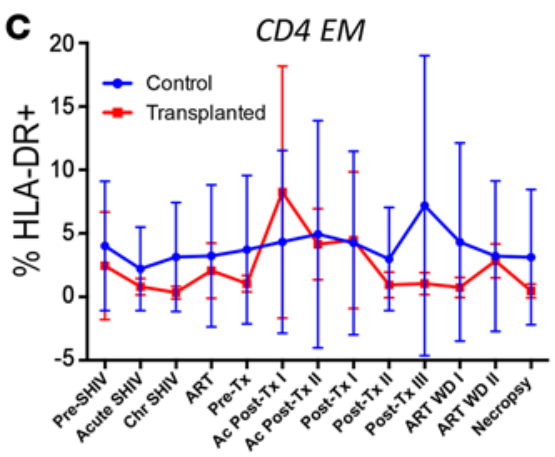

$\mathbf{F}_{100}$

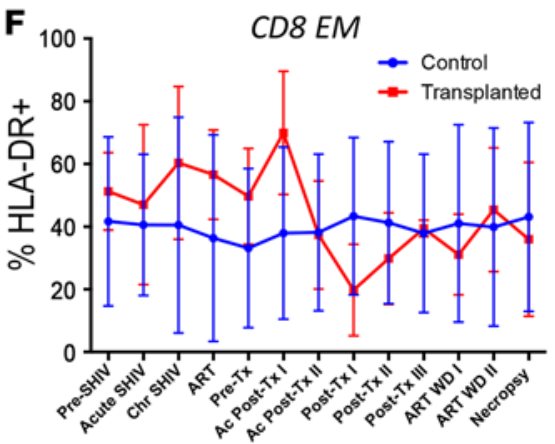

Figure 6. Significant increase in CD4+HLA-DR+ and CD8 ${ }^{+} H L A-D R^{+}$subset proportions following autologous transplantation. At the indicated time points, flow cytometry was used to analyze batched peripheral blood mononuclear cell (PBMC) samples for expression of the activation marker HLA-DR in CD4 ${ }^{+}$ $(\mathbf{A}-\mathbf{C})$ and $C D 8^{+} T$ cells $(\mathbf{D}-\mathbf{F})$. Naive, central memory (CM), and effector memory (EM) subsets are shown. Values in $\mathbf{D}$ through I represent mean \pm SD. ${ }^{*} P<0.05,{ }^{* *} P<0.01$ by 2 -tailed Mann-Whitney test. Time points along the $x$ axes are defined in Supplemental Table 1.

homeostasis and functional memory responses is an essential safeguard to the VL rebound observed in the Boston patients, and other cases of VL rebound following long-term HIV remission (56, 57). More broadly, our data strongly suggest that mucosal immune functionality should be a primary emphasis for transplantation/gene therapy interventions, and any HIV cure strategy including an ATI component.

Our QVOA and TILDA reservoir measurements suggest that myeloablative conditioning does not significantly impact the size of the peripheral latent viral reservoir. Coupled with the significant perturbations to the immune system that we observed following TBI, we conclude that nonmyeloablative/reduced intensity conditioning regimens such as busulfan should be the focus of HIV cure clinical trials. Busulfan-based conditioning regimens are currently under evaluation in multiple such trials, for example NCT01734850 and NCT02500849. Our data suggest that this approach will offer significantly lower toxicity to patients with sufficient levels of stem cell engraftment, and a minimal impact on reduction of latent viral reservoirs.

In summary, we reveal the immunological mechanisms underlying the ability of viral reservoirs to persist following autologous transplantation in a macaque model. Although the conditioning regimen facilitates stem cell engraftment and likely impacts the size of the latent reservoir, this comes at the cost of loss of virusspecific immunity, and decreased mucosal integrity. Our findings emphasize the importance of minimizing the extent of immune exhaustion after autologous or allogeneic transplantation, in order to facilitate rapid and full restoration of the immune system. In addition, these data also highlight the importance of HIV protection for the transplanted cells, as was likely key to the functional cure of the Berlin patient.

\section{Methods}

Study design. Ten male juvenile pigtail macaques were utilized in this study. The animals were sourced from New Iberia Research Center and SNBL-USA. In order to minimize the effects of subjective bias, animals were entered without prior knowledge of study-relevant factors, including lymphocyte counts and response to our stem cell mobilization regimen. All 10 animals were treated as single experimental units, and were analyzed as 2 experimental groups of 5 animals each, whose size was designed to inform the impact of autologous hematopoietic stem cell transplants while accounting for potential animal-to-animal variability. 
A
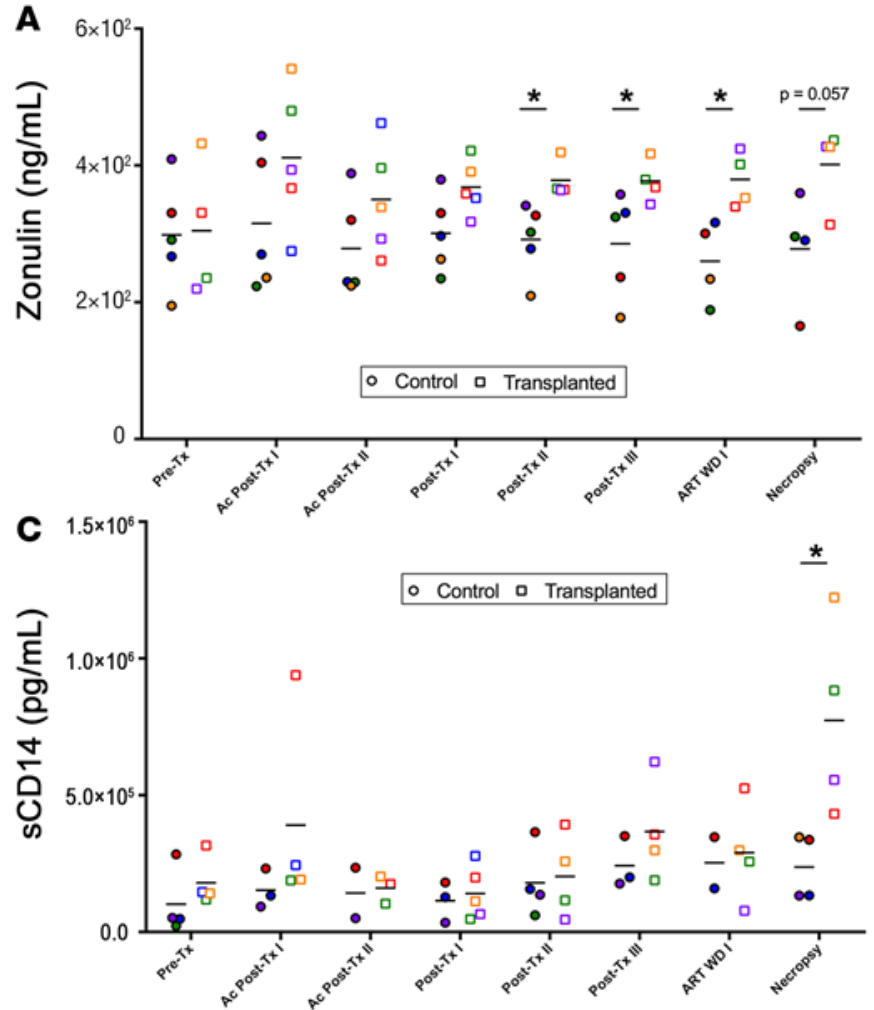

D
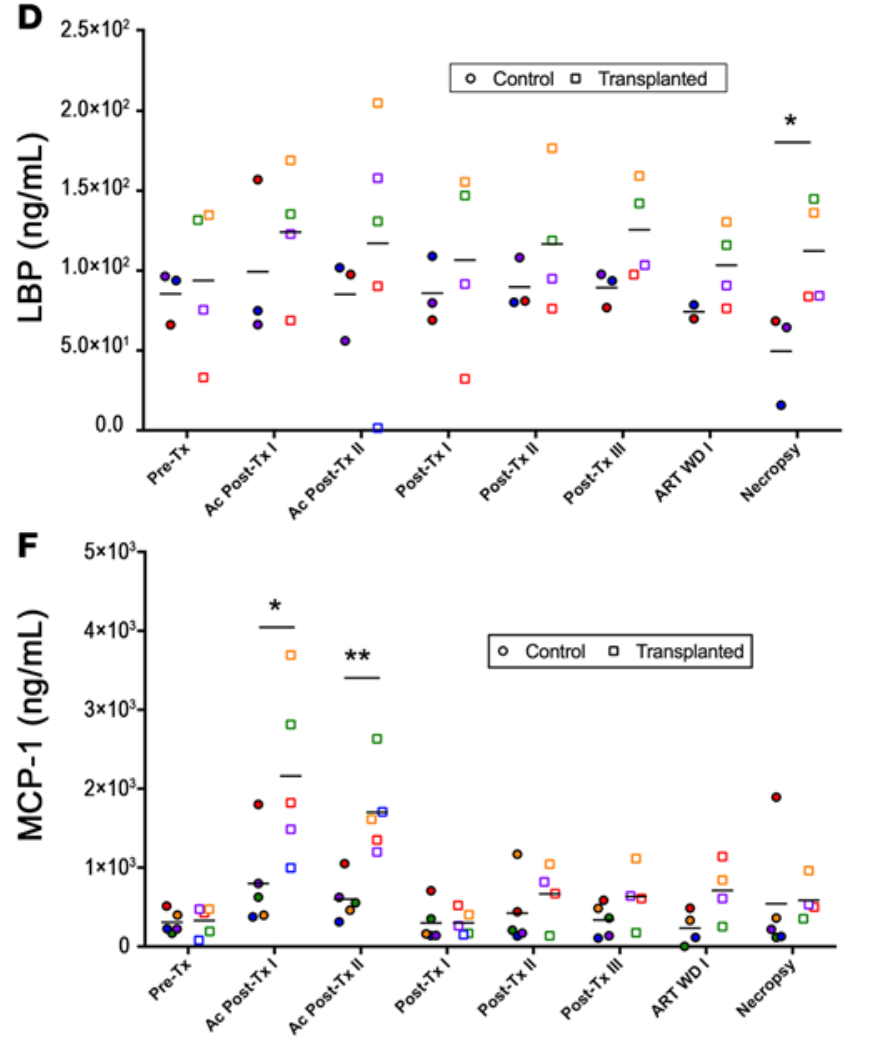

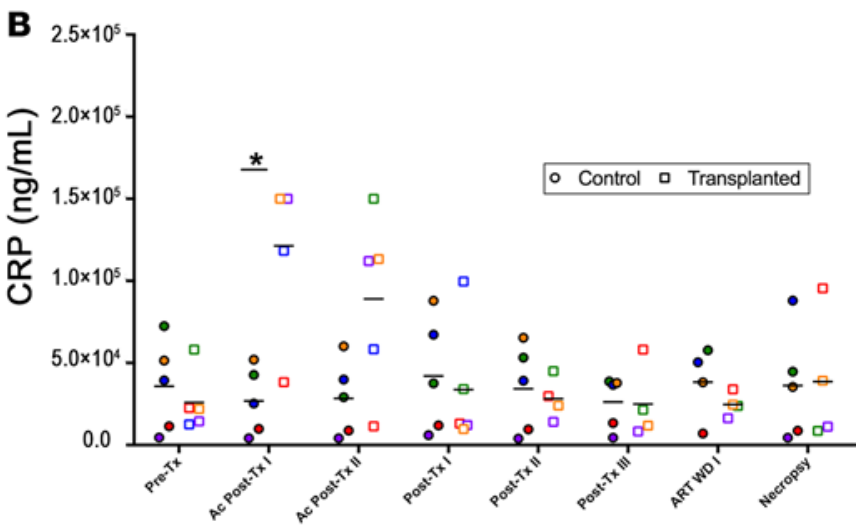

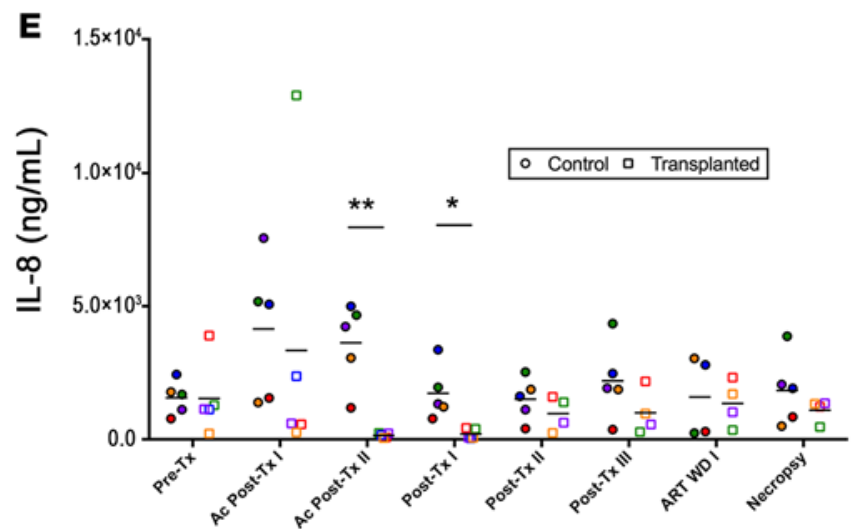

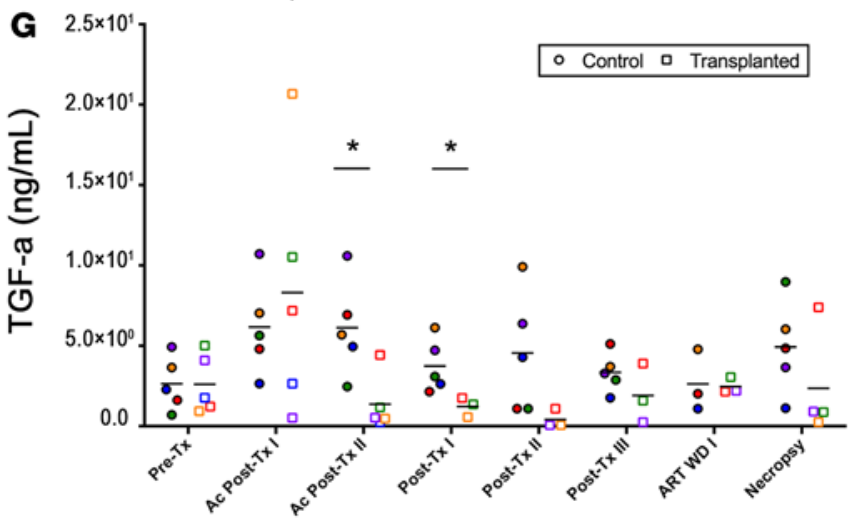

Figure 7. Elevated levels of inflammatory cytokines, growth factors, and microbial translocation markers following autologous transplant. Serum was collected at the indicated time points following autologous transplantation in transplanted (open squares) and matched control animals (closed circles). Shown are measurements of zonulin (A), C-reactive protein (CRP, B), soluble CD14 (sCD14) (C), lipopolysaccharide binding protein (LBP, D), soluble IL-8 (E), monocyte chemoattractant protein-1 (MCP-1, F), and TCF- $\alpha(\mathbf{C})$. Samples with undetectable levels of target protein(s) were omitted from analyses. The levels of CRP in 3 samples were too high to be measured in our assay, and were assigned a value of $150,000 \mathrm{ng} / \mathrm{ml}$, equivalent to twice the highest standard. Horizontal lines represent mean values for each group. ${ }^{*} P<0.05$, ${ }^{* *} P<0.01$ by 2 -tailed Mann-Whitney test. Near-significant $P$ values are also indicated. Time points along the $x$ axes are defined in Supplemental Table 1. 


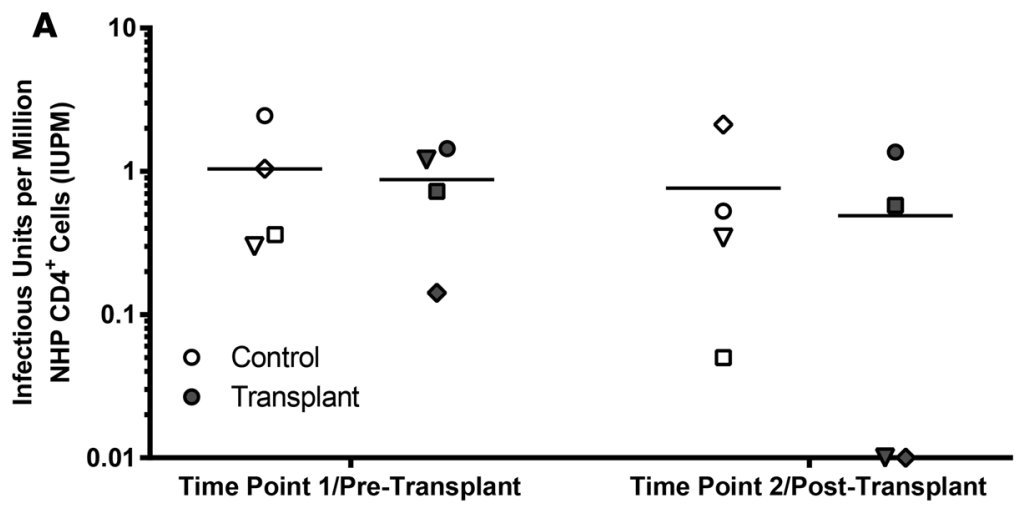

B

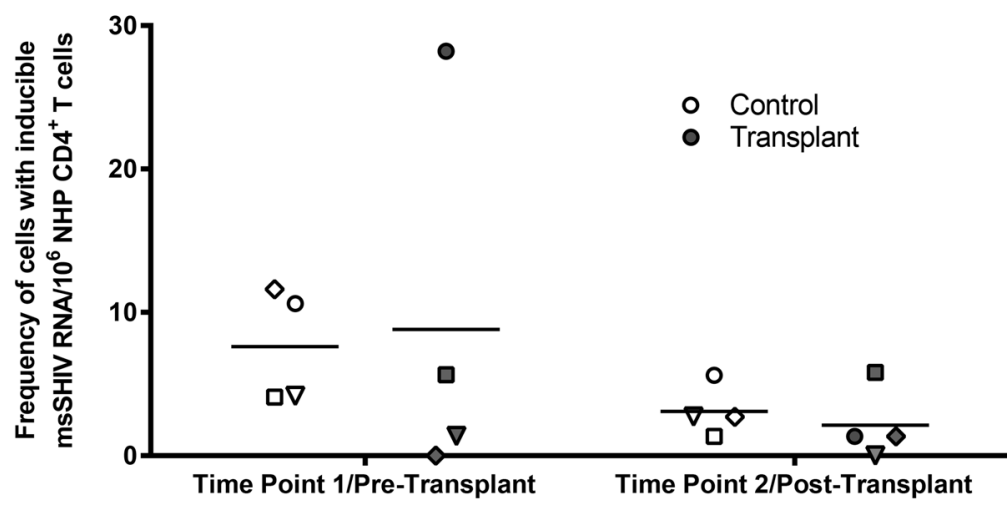

Figure 8. Transplantation does not increase the size of the latent simian-human immunodeficiency virus reservoir. At time points immediately prior to transplantation (Time Point 1, 6 months following initiation of combination antiretroviral therapy [CART]), and 4-5 months after transplantation (Time Point 2, 10-11 months following initiation of CART), apheresis was performed to collect large numbers of lymphocytes from transplanted and control animals. (A) Quantitative viral outgrowth assay (QVOA) from Time Points 1 and 2 . Results are expressed as infectious units per million cells (IUPM). Samples that were undetectable by QVOA were plotted as 0.01 IUPM for graphing purposes. (B) Tat/rev-induced limiting dilution assay, measured from same cell samples as in $\mathbf{A}$. Horizontal lines represent mean values for each group. msSHIV RNA, multispliced simian-human immunodeficiency virus RNA; NHP, nonhuman primate.

Animal IDs for the control cohort were Z09087, Z09106, Z09192, A11201, and Z09204. Animal IDs for the transplanted cohort were Z09144, Z08214, Z09125, A11200, and Z09196. The primary endpoints (VL rebound in blood and tissues following cART withdrawal and lymphoid and myeloid lineage recovery kinetics) and secondary endpoints (correlations between VL rebound and peripheral blood cell phenotypes and serum markers) were chosen prospectively. Age ranges for the control and transplanted groups were 3.9-5.8 and 3.9-5.5 years, respectively. Animals received CD34+ cell doses ranging from 2.08 million to 6.45 million per kilogram body weight. The conditioning regimen for each transplant consisted of a fractionated dose of 1,020 cGy total body irradiation, as previously described (17). Data collection continued through necropsy for each animal, based on our definition of VL rebound in tissues that could not be collected until study endpoint. Two animals were excluded partway through study, 1 from each of the 2 experimental groups. The first animal, ID A11201 from the control group, was excluded following diagnosis of congenital growth plate dysplasia. The second animal, ID Z09125 from the transplanted group, was excluded following receipt of a malaria-contaminated blood transfusion during transplant recovery. Data from ID Z09125 were excluded following the acute post-transplant I (Ac Post-Tx I) time point, and data from ID A11201 ART withdrawal time points I and II (ART WD I and ART WD II) were not available. Data from these animals were excluded in analyses of correlates of post-cART VL rebound. The details of the different time points and their abbreviations are listed in Supplemental Table 1.

SHIV challenge, plasma VL assays, complete blood cell counts, and anti-SHIV Ab titers. Intravenous inoculation with 9500 TCID50 SHIV-1157ipd3N4 (provided by Ruth Ruprecht, Texas Biomedical Research Institute), administration of cART (tenofovir [PMPA], emtricitabine [FTC], and raltegravir), and measurement of plasma VLs and absolute $\mathrm{CD} 4^{+}$and $\mathrm{CD} 8^{+} \mathrm{T}$ cell counts were conducted as described previously $(11,14$, 58). PMPA and FTC were gifts of Gilead Sciences, and raltegravir was a gift of Merck. SIVmac239 whole virus-specific and HIV-1 SF162 gp120-specific Ab titers were calculated as the reciprocal of the highest serum dilution $(1: 100,1: 200$, etc.) that resulted in an optical density reading greater than the average from serum from 3 SHIV-negative macaques, plus 3 standard deviations as previously described (59).

Tissue VL assays. Collection of the indicated tissues in Figure 1D was conducted in close consultation with the Washington National Primate Research Center (WaNPRC). Animals were not perfused prior to tissue collection, in order to minimize the time between collection and processing. Whole tissue sections of approximately $5 \mathrm{~mm}^{3}$ were immersed in RNAlater (Thermo Fisher) and stored overnight at $4^{\circ} \mathrm{C}$. The following morning, fully immersed tissues were blotted dry on paper towels, moved to cryovials, snap frozen in liquid nitrogen, and stored at $-80^{\circ} \mathrm{C}$. RNeasy Plus Mini and DNA Blood Mini kits (Qiagen) were used to isolate RNA and DNA, respectively, following homogenization of single $5-\mathrm{mm}^{3}$ sections of tissue in 1 $\mathrm{ml}$ RNeasy RLT Plus Buffer containing $\beta$-mercaptoethanol. Tissues were homogenized using a Precellys 
24 homogenizer and CK28-R hard tissue homogenizing beads (Bertin Corp.). SHIV was quantified from extracted total DNA as described previously (22). Unspliced SHIV RNA was measured similarly, except that the normalized SHIV RNA copy number (Figure 1D) was calculated by normalizing to the crossing threshold of macaque RNase P subunit p30 RNA.

Flow cytometry. Three multicolor panels were used to assess cell-surface and intracellular protein markers in this study. The T cell panel included CD3-PerCP clone SP34-2, CCR7-PE clone 3D12, CD45-BUV395 clone D058-1283 (Thermo Fisher), CCR5-APC clone 3A9, Ki67-AF700 clone B56, CD95-PE-Cy7 clone DX2, CD45RA-V450 clone 5H9, HLA-DR-BV711 clone G46-6, CD8-BUV737 clone SK1 (Becton Dickinson), PD-1-APC-eFluor780 clone eBioJ105 (eBioscience), CD28-ECD clone CD28.2 (Beckman Coulter), and CD4-BV570 clone OKT4 (BioLegend). The innate immune panel included CD3-PerCP clone SP34-2, CD45-BUV395 clone D058-1283 (Thermo Fisher), CD11c-AF700 clone 3.9 (eBioscience), CD11b-APCCy7 clone ICRF44, HLA-DR-PE-CF594 clone G46-6, CD123-BV650 clone 7G3, CD14-BV786 clone M5E2, CD16-BUV737 clone 3G8 (Becton Dickinson), CD20-BV570 clone 2H7 (BioLegend), and CD33VioBlue clone AC104.3E3 (Miltenyi Biotec). The ICP panel included CD3-BV650 clone SP34-2, CCR7APC clone 150503, CD8-BV711 clone RTP4, CD95-BUV737 clone DX2, CTLA4 (CD152)-PE-CF594 clone BIN13 (Becton Dickinson), CD4-Q-dot 605 clone S3.5 (Invitrogen), CD28-AF700 clone CD28.2, PD-1-PE-Cy7 clone EH12.2H7 (BioLegend), LAG3 PerCP eFluor710 clone 3DS223H, CD150-FITC clone A12(7D4), and TIGIT-PE clone MBSA43 (eBioscience). All panels also included a live/dead stain. Batched cell samples from the time points described in Supplemental Table 1 were stained with the above markers, as previously described (22). Acquisition was performed on LSR II and Fortessa instruments (Becton Dickinson). Flow cytometry data were analyzed using FlowJo (Tree Star).

Serum analyses. Serum samples were collected at the time points indicated in Supplemental Table 1 using serum separator tubes, cryopreserved, and batch analyzed. An NHP-specific, multiplexed Luminex bioassay (EMD Millipore) was used to quantify serum levels of IL-8, IL-15, MCP-1, TGF- $\alpha$, IL-17A (Figure 7 and Supplemental Figure 4), and 19 other cytokines (data not shown). ELISA was used to quantify serum levels of LBP (Antibodies-Online Inc.), zonulin (MyBioSource Inc.), CRP (Life Diagnostics Inc), sCD14 (Thermo Fisher), and LPS (Lonza Inc.). Values were interpolated relative to a standard curve for each kit. For 3 samples that were above the measurable range for CRP, an arbitrary value of 150,000 ng/ml, twice the highest standard, was assigned.

Statistics. Comparisons between untransplanted and transplanted animals were performed using a nonparametric, unpaired, 2-tailed Mann-Whitney test, as indicated in the figures. Association between each parameter and the peak VL was investigated using a nonparametric Spearman correlation test. The obtained nominal $P$ values were adjusted for multiple testing using the Benjamini-Hochberg procedure (60). This method controls the false discovery rate, which was set to 0.25 . These tests were performed using $\mathrm{R}$ and Prism software.

Viral reservoir assays. TILDA was adapted from Procopio et al. (61) to detect inducible multiply spliced SHIV RNA: untouched CD4 ${ }^{+} \mathrm{T}$ cells from untransplanted and transplanted animals at pre-Tx and post-Tx time points (Supplemental Table 1) were subjected to negative magnetic selection (STEMCELL Technologies) and activated for 12 hours with $100 \mathrm{ng} / \mathrm{ml}$ PMA and $1 \mu \mathrm{g} / \mathrm{ml}$ ionomycin (both from Sigma-Aldrich). After activation, cells were serially diluted to $18 \times 10^{6}$ cells $/ \mathrm{ml}, 9 \times 10^{6}$ cells $/ \mathrm{ml}, 3 \times 10^{6} \mathrm{cells} / \mathrm{ml}$, and 1 $\times 10^{6} \mathrm{cells} / \mathrm{ml}$ in culture medium. The next steps (preamplification and real-time PCR) are described in Procopio et al. (61). The sequences of the oligonucleotides for the preamplification were: rev, 5'-GGATCTGTCTCTGTCTCTCTCTCCACC-3' and tat1.4, 5'-TGGCAGGAAGAAGCGGAGA-3'. The sequences of the oligonucleotides and probe for the real-time PCR were: rev, 5'-GGATCTGTCTCTGTCTCTCTCTCCACC-3'; tat2, 5'-ACAGTCAGACTCATCAAGTTTCTCTATCAAAGCA-3'; and Probe SHIV, 5'-/56FAM/TTCCTTCGG /ZEN/GCCTGTCGGCTCCC /3IABkFQ/-3'. All primers and probes were synthesized by IDT. The real-time PCR reaction was carried out in a Light Cycler 480 II (Roche Life Science). Positive wells at each dilution were counted and the maximum likelihood method was used to calculate the frequency of cells with inducible HIV msRNA (http://bioinf.wehi.edu.au/software/elda).

QVOAs were designed for outgrowth of SHIV-infected cells based on previously published protocols using HIV-infected samples (62), with the following modifications. Primary human peripheral blood mononuclear cells (PBMCs; Biological Specialty Corporation) were used for coculture following magnetic beadbased CD8 depletion. Pigtail macaque $\mathrm{CD} 4^{+}$cells were isolated by magnetic bead-based negative selection (STEMCELL Technologies). Well sizes for QVOA experiments were dependent on the yield of NHP CD4 ${ }^{+}$ 
cells from pre- and post-transplant apheresis collections; the minimum well size for routine assays was $1 \times 10^{5} \mathrm{NHP} \mathrm{CD}^{+}$cells. An additional small-wells experiment, incorporating well sizes of $4 \times 10^{4}, 8 \times$ $10^{3}$, and $3.2 \times 10^{2} \mathrm{NHP} \mathrm{CD} 4^{+}$cells, was utilized for animals with larger reservoirs. Human PBMCs were stimulated with anti-CD3 Ab clone UCHT1, while clone SP34 was used to stimulate macaque cells (Becton Dickinson). Tissue culture supernatants were collected over the course of 1 month in culture, and viral outgrowth was measured by SIV Gag p27 ELISA (Zeptometrix) and measurement of unspliced SHIV RNA as described above. Our criteria for a positive sample were (a) greater than $20 \mathrm{pg} / \mathrm{ml}$ by ELISA at more than 2 consecutive time points, or (b) less than $20 \mathrm{pg} / \mathrm{ml}$ by ELISA, but measurable SHIV RNA at more than 2 consecutive time points. Samples that were ELISA negative and SHIV RNA positive at 2 or fewer consecutive time points were scored as negative. Infectious units per million (IUPM) calculations were derived via a web-based program as previously described (63).

Study approval and ethical treatment of animals. This study was carried out in strict accordance with the recommendations in the Guide for the Care and Use of Laboratory Animals of the NIH (The Guide). The protocol was approved by the IACUCs of the Fred Hutchinson Cancer Research Center and University of Washington, protocol number 3235-03. All animals were housed at and included in standard monitoring procedures prescribed by the WaNPRC. This included at least twice-daily observation by animal technicians for basic husbandry parameters (e.g., food intake, activity, stool consistency, overall appearance) as well as daily observation by a veterinary technician and/or veterinarian. Animals were housed in cages approved by The Guide and in accordance with Animal Welfare Act regulations. Animals were fed twice daily, and were fasted for up to 14 hours prior to sedation. Environmental enrichment included grouping in compound, large activity, or run-through connected cages, perches, toys, food treats, and foraging activities. If a clinical abnormality was noted by WaNPRC personnel, standard WaNPRC procedures were followed to notify the veterinary staff for evaluation and determination for admission as a clinical case. Animals were sedated by administration of ketamine $\mathrm{HCl}$ and/or Telazol and supportive agents prior to all procedures. Following sedation, animals were monitored according to WaNPRC standard protocols. WaNPRC surgical support staff are trained and experienced in the administration of anesthetics and have monitoring equipment available to assist: electronic monitoring of heart rate, respiration, and blood oxygenation; audible alarms and LCD readouts; monitoring of blood pressure, temperature, etc. For minor procedures, the presence or absence of deep pain was tested by the toe-pinch reflex. The absence of response (leg flexion) to this test indicates adequate anesthesia for this procedure. Similar parameters were used in cases of general anesthesia, including the loss of palpebral reflexes (eye blink). Analgesics were provided as prescribed by the Clinical Veterinary staff for at least 48 hours after the procedures, and could be extended at the discretion of the clinical veterinarian, based on clinical signs. Decisions to euthanize animals were made in close consultation with veterinary staff, and were performed in accordance with guidelines as established by the American Veterinary Medical Association Panel on Euthanasia (2013). Prior to euthanasia, animals were first rendered unconscious by administration of ketamine $\mathrm{HCl}$.

\section{Author contributions}

HPK is the principal investigator of the study and designed and coordinated the overall execution of the project. CWP designed the animal experiments, which were coordinated with PP. CWP, PP, and SLH analyzed the longitudinal VL, T cell, and serology data. JK performed the QVOA, which was developed by JK and CWP. AB and RDM directed the collection of tissues at necropsy. CEM and JK performed the tissue nucleic acid isolation assay, which was developed by CEM, JK, MLH, KRJ, and CWP. TAP performed the serum Luminex and microbial translocation assays, which were designed and developed by NRK. CB and WO performed the flow cytometry experiments, which were designed by SD, NRK, $C B$, and RPS. CB and AFM performed statistical analyses. CB performed the TILDAs. CWP, CB, RPS, and HPK wrote the manuscript.

\section{Acknowledgments}

The authors thank Helen Crawford for help in preparing this manuscript; Veronica Nelson, Erica Curry, and Kelvin Sze for outstanding support in our pigtail macaque studies; Andrea Repetto, and Sowmya Reddy for processing of macaque samples; and Joel Ahrens for assistance with sample collections. We also thank Tae-Wook Chun for his expertise and support in development of the macaque-adapted quantitative viral outgrowth assay. 
This study was supported by grants from the NIH National Institute of Allergy and Infectious Diseases (U19 AI096111 and UM1 AI126623 to HPK and KRJ) and National Heart, Lung, and Blood Institute (R01 HL116217 and U19 HL129902 to HPK). This study was also supported by NIH P51 OD010425 and UW/FHCRC CFAR AI027757. HPK is a Markey Molecular Medicine Investigator and received support as the inaugural recipient of the José Carreras/E. Donnall Thomas Endowed Chair for Cancer Research and the Fred Hutch Endowed Chair for Cell and Gene Therapy.

Address correspondence to: Hans-Peter Kiem, Fred Hutchinson Cancer Research Center, 1100 Fairview Avenue N, Mail Stop D1-100, PO Box 19024, Seattle, Washington 98109-1024, USA. Phone: 206.667.4425; E-mail: hkiem@fhcrc.org.

1. Murray AJ, Kwon KJ, Farber DL, Siliciano RF. The latent reservoir for HIV-1: how immunologic memory and clonal expansion contribute to HIV-1 persistence. J Immunol. 2016;197(2):407-417.

2. Deeks SG, et al. International AIDS Society global scientific strategy: towards an HIV cure 2016. Nat Med. 2016;22(8):839-850.

3. Hütter G, et al. Long-term control of HIV by CCR5 Delta32/Delta32 stem-cell transplantation. N Engl J Med. 2009;360(7):692-698.

4. Allers K, et al. Evidence for the cure of HIV infection by CCR5 $\Delta 32 / \Delta 32$ stem cell transplantation. Blood. 2011;117(10):2791-2799.

5. Petz LD, et al. Progress toward curing HIV infection with hematopoietic cell transplantation. Stem Cells Cloning. 2015;8:109-116.

6. Hütter G, Ganepola S. Eradication of HIV by transplantation of CCR5-deficient hematopoietic stem cells. ScientificWorldJournal. 2011;11:1068-1076.

7. Hütter G. More on shift of HIV tropism in stem-cell transplantation with CCR5 delta32/delta32 mutation. NEngl J Med. 2014;371(25):2437-2438.

8. Hütter G. HIV ${ }^{+}$patients and HIV eradication - allogeneic transplantation. Expert Rev Hematol. 2016;9(7):615-616

9. Alvarnas JC, et al. Autologous hematopoietic cell transplantation for HIV-related lymphoma: results of the BMT CTN 0803/ AMC 071 trial. Blood. 2016;128(8):1050-1058.

10. Kuritzkes DR. Hematopoietic stem cell transplantation for HIV cure. J Clin Invest. 2016;126(2):432-437.

11. Peterson CW, et al. Robust suppression of env-SHIV viremia in Macaca nemestrina by 3-drug ART is independent of timing of initiation during chronic infection. J Med Primatol. 2013;42(5):237-246.

12. Younan PM, et al. Lentivirus-mediated gene transfer in hematopoietic stem cells is impaired in SHIV-infected, ART-treated nonhuman primates. Mol Ther. 2015;23(5):943-951.

13. Song RJ, et al. Molecularly cloned SHIV-1157ipd3N4: a highly replication- competent, mucosally transmissible R5 simianhuman immunodeficiency virus encoding HIV clade C Env. J Virol. 2006;80(17):8729-8738.

14. Ho O, et al. Pathogenic infection of Macaca nemestrina with a CCR5-tropic subtype-C simian-human immunodeficiency virus. Retrovirology. 2009;6:65.

15. Shea-Donohue T, et al. Mechanisms involved in the development of the chronic gastrointestinal syndrome in nonhuman primates after total-body irradiation with bone marrow shielding. Radiat Res. 2016;185(6):591-603.

16. Donahue RE, et al. Discordance in lymphoid tissue recovery following stem cell transplantation in rhesus macaques: an in vivo imaging study. Blood. 2015;126(24):2632-2641.

17. Peterson CW, et al. Multilineage polyclonal engraftment of Cal-1 gene-modified cells and in vivo selection after SHIV infection in a nonhuman primate model of AIDS. Mol Ther Methods Clin Dev. 2016;3:16007.

18. Fraser C, Hollingsworth TD, Chapman R, de Wolf F, Hanage WP. Variation in HIV-1 set-point viral load: epidemiological analysis and an evolutionary hypothesis. Proc Natl Acad Sci USA. 2007;104(44):17441-17446.

19. Mavigner M, et al. Persistence of virus reservoirs in ART-treated SHIV-infected rhesus macaques after autologous hematopoietic stem cell transplant. PLoS Pathog. 2014;10(9):e1004406.

20. North TW, et al. Viral sanctuaries during highly active antiretroviral therapy in a nonhuman primate model for AIDS. J Virol. 2010;84(6):2913-2922.

21. Zink MC, et al. High viral load in the cerebrospinal fluid and brain correlates with severity of simian immunodeficiency virus encephalitis. J Virol. 1999;73(12):10480-10488.

22. Peterson CW, et al. Lack of viral control and development of combination antiretroviral therapy escape mutations in macaques after bone marrow transplantation. AIDS. 2015;29(13):1597-1606.

23. Hazenberg MD, et al. T-cell division in human immunodeficiency virus (HIV)-1 infection is mainly due to immune activation: a longitudinal analysis in patients before and during highly active antiretroviral therapy (HAART). Blood. 2000;95(1):249-255.

24. Mohri H, Bonhoeffer S, Monard S, Perelson AS, Ho DD. Rapid turnover of T lymphocytes in SIV-infected rhesus macaques. Science. 1998;279(5354):1223-1227.

25. Wolthers KC, Schuitemaker H, Miedema F. Rapid CD4 ${ }^{+}$T-cell turnover in HIV-1 infection: a paradigm revisited. Immunol Today. 1998;19(1):44-48.

26. Fromentin R, et al. CD4 ${ }^{+}$T cells expressing PD-1, TIGIT and LAG-3 contribute to HIV persistence during ART. PLoS Pathog. 2016;12(7):e1005761.

27. Blackburn SD, et al. Coregulation of $\mathrm{CD}^{+} \mathrm{T}$ cell exhaustion by multiple inhibitory receptors during chronic viral infection. Nat Immunol. 2009;10(1):29-37.

28. DeBo RJ, et al. Late effects of total-body gamma irradiation on cardiac structure and function in male rhesus macaques. Radiat Res. 2016;186(1):55-64.

29. Borgmann A, et al. Influence of fractionated total body irradiation on mucosal toxicity in intensified conditioning regimens for autologous bone marrow transplantation in pediatric cancer patients. Klin Padiatr. 1994;206(4):299-302. 
30. Tardieu C, Cowen D, Thirion X, Franquin JC. Quantitative scale of oral mucositis associated with autologous bone marrow transplantation. Eur J Cancer, B, Oral Oncol. 1996;32B(6):381-387.

31. Brenchley JM, et al. Microbial translocation is a cause of systemic immune activation in chronic HIV infection. Nat Med. 2006;12(12):1365-1371.

32. Sandler NG, et al. Plasma levels of soluble CD14 independently predict mortality in HIV infection. J Infect Dis. 2011;203(6):780-790.

33. Klatt NR, et al. Compromised gastrointestinal integrity in pigtail macaques is associated with increased microbial translocation, immune activation, and IL-17 production in the absence of SIV infection. Mucosal Immunol. 2010;3(4):387-398.

34. Somsouk M, et al. Gut epithelial barrier and systemic inflammation during chronic HIV infection. AIDS. 2015;29(1):43-51.

35. Klatt NR, Chomont N, Douek DC, Deeks SG. Immune activation and HIV persistence: implications for curative approaches to HIV infection. Immunol Rev. 2013;254(1):326-342.

36. Wang W, Wu F, Cong Z, Liu K, Qin C, Wei Q. The secretion of IL-22 from mucosal NKp44+ NK cells is associated with microbial translocation and virus infection in SIV/SHIV-infected Chinese macaques. J Immunol Res. 2014;2014:387950

37. Ortiz AM, et al. IL-21 and probiotic therapy improve Th17 frequencies, microbial translocation, and microbiome in ARV-treated, SIV-infected macaques. Mucosal Immunol. 2016;9(2):458-467.

38. Zevin AS, McKinnon L, Burgener A, Klatt NR. Microbial translocation and microbiome dysbiosis in HIV-associated immune activation. Curr Opin HIV AIDS. 2016;11(2):182-190.

39. Tchao NK, Turka LA. Lymphodepletion and homeostatic proliferation: implications for transplantation. Am J Transplant. 2012;12(5):1079-1090.

40. Boyman O, Létourneau S, Krieg C, Sprent J. Homeostatic proliferation and survival of naïve and memory T cells. Eur J Immunol. 2009;39(8):2088-2094.

41. Orendi JM, et al. Activation and cell cycle antigens in $\mathrm{CD}^{+}$and $\mathrm{CD} 8^{+} \mathrm{T}$ cells correlate with plasma human immunodeficiency virus (HIV-1) RNA level in HIV-1 infection. J Infect Dis. 1998;178(5):1279-1287.

42. Cockerham LR, et al. $\mathrm{CD} 4^{+}$and $\mathrm{CD} 8^{+} \mathrm{T}$ cell activation are associated with HIV DNA in resting CD4 ${ }^{+} \mathrm{T}$ cells. PLoS ONE 2014;9(10):e110731.

43. Trautmann L, et al. Profound metabolic, functional, and cytolytic differences characterize HIV-specific CD8 T cells in primary and chronic HIV infection. Blood. 2012;120(17):3466-3477.

44. Hazenberg MD, et al. T-cell receptor excision circle and T-cell dynamics after allogeneic stem cell transplantation are related to clinical events. Blood. 2002;99(9):3449-3453.

45. Eyrich M, et al. Onset of thymic recovery and plateau of thymic output are differentially regulated after stem cell transplantation in children. Biol Blood Marrow Transplant. 2005;11(3):194-205.

46. Klatt NR, et al. Dynamics of simian immunodeficiency virus SIVmac239 infection in pigtail macaques. $J$ Virol. 2012;86(2):1203-1213.

47. Fukazawa Y, et al. B cell follicle sanctuary permits persistent productive simian immunodeficiency virus infection in elite controllers. Nat Med. 2015;21(2):132-139.

48. Perreau M, et al. Exhaustion of bacteria-specific CD4 T cells and microbial translocation in common variable immunodeficiency disorders. J Exp Med. 2014;211(10):2033-2045.

49. Johnston C, Harrington R, Jain R, Schiffer J, Kiem HP, Woolfrey A. Safety and efficacy of combination antiretroviral therapy in human immunodeficiency virus-infected adults undergoing autologous or allogeneic hematopoietic cell transplantation for hematologic malignancies. Biol Blood Marrow Transplant. 2016;22(1):149-156.

50. Topalian SL, et al. Safety, activity, and immune correlates of anti-PD-1 antibody in cancer. N Engl J Med. 2012;366(26):24432454 .

51. Chen L, Han X. Anti-PD-1/PD-L1 therapy of human cancer: past, present, and future. J Clin Invest. 2015;125(9):3384-3391.

52. Saunders KO, et al. Broadly neutralizing human immunodeficiency virus type 1 antibody gene transfer protects nonhuman primates from mucosal simian-human immunodeficiency virus infection. $J$ Virol. 2015;89(16):8334-8345.

53. Derdeyn CA, Moore PL, Morris L. Development of broadly neutralizing antibodies from autologous neutralizing antibody responses in HIV infection. Curr Opin HIV AIDS. 2014;9(3):210-216.

54. Lutz M, Mielke S. New perspectives on the use of mTOR inhibitors in allogeneic haematopoietic stem cell transplantation and graft-versus-host disease. Br J Clin Pharmacol. 2016;82(5):1171-1179.

55. Mannick JB, et al. mTOR inhibition improves immune function in the elderly. Sci Transl Med. 2014;6(268):268ra179.

56. Henrich TJ, et al. Antiretroviral-free HIV-1 remission and viral rebound after allogeneic stem cell transplantation: report of 2 cases. Ann Intern Med. 2014;161(5):319-327.

57. Persaud D, et al. Absence of detectable HIV-1 viremia after treatment cessation in an infant. N Engl J Med. 2013;369(19):1828-1835.

58. Polacino P, et al. Immunogenicity and protective efficacy of Gag/Pol/Env vaccines derived from temporal isolates of SIVmne against cognate virus challenge. J Med Primatol. 2007;36(4-5):254-265.

59. Hu SL, et al. Protection of macaques against simian AIDS by immunization with a recombinant vaccinia virus expressing the envelope glycoproteins of simian type D retrovirus. Proc Natl Acad Sci USA. 1989;86(18):7213-7217.

60. Benjamini Y, Hochberg Y. Controlling the false discovery rate - a practical and powerful approach to multiple testing. J Roy Stat Soc B Met. 1995;57(1):289-300.

61. Procopio FA, et al. A novel assay to measure the magnitude of the inducible viral reservoir in HIV-infected individuals. EBioMedicine. 2015;2(8):874-883.

62. Chun TW, et al. Quantification of latent tissue reservoirs and total body viral load in HIV-1 infection. Nature. 1997;387(6629):183-188.

63. Rosenbloom DI, Elliott O, Hill AL, Henrich TJ, Siliciano JM, Siliciano RF. Designing and interpreting limiting dilution assays: general principles and applications to the latent reservoir for human immunodeficiency virus-1. Open Forum Infect Dis. 2015;2(4):ofv123. 